\title{
PERANCANGAN SISTEM INFORMASI JASA PERBAIKAN BRANKAS BERBASIS WEBSITE PADA AHLIBRANGKAS.COM
}

\author{
Ahmad Rais Ruli \\ Universitas Bina Sarana Informatika (BSI) \\ Jl. Kamal Raya no 18. Ringroad Barat. Cengkareng. Jakarta Barat. \\ (021) 54376398 Mobile 085710002740 \\ Website: www.bsi.ac.id ,E-mail: ahmad.aul@bsi.ac.id
}

\begin{abstract}
Abstrak - Ahlibrangkas.com yang bergerak di bidang jasa perbaikan brankas yang masih menggunakan sistem manual pada proses pemesananya. Pada sistem manual ahlibrangkas.com, juga masih sering ditemukan konsumen yang mengeluhkan karena harus menelpon terlebih dahulu untuk menanyakan proses pesan mengenai harga,waktu dan tempat. Sistem Informasi jasa perbaikan brankas berbasis website akan membantu serta memudahkan konsumen dalam melakukan pemesanan, dan memudahkan konsumen yang ingin melakukan pembayaran secara langsung dengan metode pembayaran yang digunakan. Agar proses transaksi konsumen semakin akurat, maka sistem ini juga memiliki sistem admin secara online. Sistem admin online ini juga dapat memudahkan karyawan yang sedang bertugas di lapangan, sehingga karyawan teknisi yang betugas dilapangan bisa bertanggung jawab atas transaksi yang sudah di selesaikan. Sistem informasi jasa perbaikan brankas ini dibuat secara online agar dapat menjadi salah satu pendukung dalam penerapan sistem informasi data yang lebih up to date, mengurangi tingkat kesalahan pada saat transaksi, dan menyimpan serta mengelola data menjadi sebuah data pendukung utama dalam pembuatan berbagai laporan.
\end{abstract}

Kata kunci: Brangkas, Perancangan System, Website.

\section{Pendahuluan}

Implementasi Sistem informasi saat ini hampir sudah diterapkan diberbagai perusahan dan organisasi di Indonesia sesuai dengan kebutuhan user, penggunaan system informasi ini pasti nya dapat memudahkan user perusahan dan organisasi dalam pencarian Data , memeriksa data sampai dengan pembuatan laporan.

Reparasi atau perbaikan brangkas selama ini masih belum menggunakan system informasi dan masih menggunakan system manual, sehingga menyulitkan user dalam pengecekan dan monitoring status barang, serta pencarian data barang yang direparasi, Karena hal itu para penyedia jasa berlomba lomba untuk dapat terus beradaptasi di pasar era globalisasi dengan cara tetap menunjukan eksistensinya melalui situs website hadir dengan tujuan memudahkan pengguna untuk melakukan pemesanan untuk jasa perbaikan secara online dengan prosedur yang mudah dan praktis digunakan.

Ahlibrankas.com adalah sebuah perusahaan yang bergerak dalam bidang jasa perbaikan brankas dan jual beli brankas berdiri pada tahun 2016 dengan beralamat Jl. Kalibata Utara V Rt.008 Rw.02 Kecamatan Pancoran Kota Jakarta Selatan, Daerah Khusus Ibukota Jakarta 12750. Selama ini Ahlibrankas.com beroperasi dengan pendekatan yang cukup modern dengan memanfaatkan website sebagai sarana promosi, tetapi hal itu masih terbilang belum cukup untuk terus menjaga pertumbuhan bisnis yang baik dimasa yang akan datang, karena seperti yang kita tahu bersama bahwa semakin banyak bisnis yang memiliki inovasi yang lebih modern dari sekedar menggunakan website sebagai media promosi. Maka dari itu Ahlibrankas.com hadir dalam inovasi baru bukan lagi menggunakan sistem manual pesan langsung melalu telepon melainkan pengguna website dapat lebih dulu mengetahui hasil diagnosa kerusakan serta estimasi biaya perbaikan brankas, pengguna juga dapat menggunakan fiture konsultasi gratis untuk mengkonfirmasi jenis kerusakan brankas yang dialami serta konsumen dapat langsung melakukan sistem pembayaran online yang memudahkan pelanggan yang ingin membayar melalui kartu kredit atau transfer bank.

\section{$2 \quad$ Landasan Teori}

\section{Konsep Dasar Sistem}

Setiap organisasi atau perusahaan memiliki sistem yang menangani serangkaian aktifitas di dalam suatu sistem agar mencapai tujuan yang optimal dalam penelitian ini penulis membuat rancangan sistem dengan menggunakan Web.Konsep dasar sistem ini menekankan sekumpulan 
elemen yang terdapat dalam suatu organisasi, perusahaan, aspek dan sudut pandang yang berbeda sesuai

dengan keterangan fungsi dalam hal-hal yang berkaitan dengan sistem yang memiliki ciri dan karakteristik tertentu. Adapun uraian dari konsep dasar system akan dijelaskan dibawah ini.

\section{Sistem}

Secara umum suatu sistem dapat diartikan sebagai suatu kumpulan atau himpunan dari unsur, komponen yang terorganisir, saling beinteraksi, saling ketergantungan satu sama lain dan terpadu untuk mencapai tujuan tertentu. Menurut Hutahaean (2015:2) mengemukakan bahwa "sistem adalah suatu

jaringan kerja dari prosedur-prosedur yang saling berhubungan, berkumpul bersama-sama untuk melakukan kegiatan atau untuk melakukan sasaran yang tertentu”.

Sistem memiliki tujuan untuk menghasilkan informasi yang nantinya informasi tersebut akan digunakan sebagai dasar pertimbangan untuk pencapaian di dalam suatu organisasi atau perusahaan. Menurut Hutahaean (2015:13) mengemukakan bahwa: Sistem informasi adalah suatu sistem di dalam suatu organisasi yang mempertemukan kebutuhan pengelolaan transaksi harian, mendukung operasi, bersifat manajerial, dan kegiatan strategi dari suatu organisasi dan menyediakan pihak luar tertentu dengan laporan-laporan yang dibutuhkan. Dari kutipan di atas disimpulkan bahwa sistem informasi merupakan kompilasi yang terdiri dari manusia, teknologi informasi, dan prosedur kerja yang saling memiliki kaitan, hubungan atau interaksi untuk melakukan pengolahan data menjadi informasi dalam suatu organisasi sebagai dasar dalam pengambilan keputusan untuk menentukan langkah di masa mendatang.

\section{Website}

Untuk mengakses internet diperlukan suatu program aplikasi Web Browser. Program aplikasi ini mempunyai kemampuan untuk menampilkan suatu Web Page yang ditulis dalam format HTML. Dua contoh program aplikasi angkatan pertama adalah Lynx dan Mosaic. Lynx adalah Web Browser yang berbasis teks. Kekurangannya adalah tidak bisa menampilkan suatu Web Page yang ditulis dalam format HTML. Mosaic adalah browser web mempopulerkan dikreditkan dengan World Wide Web. Itu juga sebelumnya klien untuk protocol seperti FTP, Usenet, dan Gopher. Yang bersih, mudah dipahami user interface, keandalan, Windows pelabuhan dan instalasi sederhana semua berkontribusi untuk membuat aplikasi yang membuka Web untuk masyarakat umum.Internet berasal dari kata Interconnection Networking yang berarti kata jaringan yang saling berhubungan. Didalam mengatur integrasi dan komunikasijaringan internet dibutuhkan sebuah protocol yang disebut TCP/IP (Transmission

Control Protocol/Internet Protocol). Secara umum internet dapat diartikan sebagai pertukaran informasi dan komunikasi. Semua informasi bisa didapatkan dengan mudah dan bebas di internet tanpa ada batasan.

\section{Unified Modeling Language (UML)}

Menurut Rosa dan Shalahuddin (2014:133), berpendapat bahwa UML(Unified Modeling Language) adalah "Salah standar bahasa yang banyak

digunakan di dunia industri untuk mendefinisikan requerement, membuat analisa \& desain, serta menggambarkan arsitektur dalam pemrograman berorintasi objek". Sedangkan Mulyani (2016:48) mengatakan UML (Unified Modeling Language) adalah "Sebuah teknik pengembangan sistem yang menggunakan bahasa grafis sebagai alat untuk pendokumentasian dan melakukan spesifikasi pada sistem". Dari beberapa penjelasan teori tersebut dapat disimpulkan bahwa UML (Unified Modeling Language) adalah bahasa yang sering digunakan untuk

membangun sebuah sistem perangkat lunak dengan melakukan penganalisaan desain dan spesifikasi dalam pemrograman berorintasi objek. UML (Unified

Modeling Language) memiliki diagram-diagram yang digunakan dalam

pembuatan aplikasi berorintasi objek, diantaranya (Rosa dan Shalahuddin,2014:155):

\section{Use Case Diagram}

Use Case Diargam merupakan pemodelan untuk melakukan (behavior) system informasi yang akan dibuat. Use case digunakan untuk mengetahui fungsi

apa saja yang ada di dalam sebuah sistem informasi dan siapa saja yang berhak menggunakan fungsi-fungsi itu. Berikut adalah simbol-simbol yang ada pada diagram use case (Rosa dan Shalahuddin, 2014:156) :

Tabel 1 Use Case Diagram (Rosa A.S dan M. Shalahudin (2014:156)

\begin{tabular}{|c|c|}
\hline Symbol & Deskripsi \\
\hline Use Case & $\begin{array}{l}\text { Fungsionalitas yang disediakan sistem } \\
\text { sebagai unit-unit yang saling tertukar } \\
\text { pesan antar unit atau aktor; biasanya } \\
\text { dinyatakan dengan menggunakan kata } \\
\text { kerja diawal frase nama Use Case }\end{array}$ \\
\hline Aktor/actor & $\begin{array}{l}\text { Orang, proses, atau sistem lain yang } \\
\text { berinteraksi dengan sistem informasi } \\
\text { yang akan dibuat diluar sistem } \\
\text { informasi yang akan dibuat itu } \\
\text { sendiri, jadi walaupun simbol dari } \\
\text { aktor adalah gambar orang, tapi aktor } \\
\text { belum tentu merupakan orang: } \\
\text { biasanya dinyatakan menggunakan } \\
\text { kata benda diawal fiase nama actor }\end{array}$ \\
\hline Asosiasi / association & $\begin{array}{l}\text { Komunikasi antara aktor dan use case } \\
\text { yang berpartisifasi pada use case atau } \\
\text { use case memiliki interaksi dengan } \\
\text { actor }\end{array}$ \\
\hline $\begin{array}{l}\text { Ekstensi/ extend } \\
-<<\text { endtent }>>\end{array}$ & $\begin{array}{l}\text { Relasi use case tambahan kesebuah } \\
\text { use case dinamakan use case yang } \\
\text { ditambahkan dapat berdiri sendiri } \\
\text { walau tanpa use case tambahan itu; } \\
\text { mirip dengan prinsip intherince pada } \\
\text { pemrograman berorientasi objek; } \\
\text { biasanya use case tambahan memiliki } \\
\text { nama depan yang sama dengan use } \\
\text { case yang ditambahkan. }\end{array}$ \\
\hline Generalisasi/generalization & $\begin{array}{l}\text { Hubungan generalisasi dan } \\
\text { spesialisasi (umum-khusus) antara dua } \\
\text { buah use case dimana fungsi yang satu }\end{array}$ \\
\hline$>$ & $\begin{array}{l}\text { adalah fungsi yang lebih umum dari } \\
\text { laainnya. }\end{array}$ \\
\hline
\end{tabular}




\section{Metodologi Penelitian}

\section{Sejarah Perusahan}

Ahlibrangkas.com adalah sebuah perusahaan yang bergerak dalam bidang jasa perbaikan dan jual beli suku cadang brankas sejak tahun 2015 .Sebagai perusahaan baru, Ahlibrangkas.com perlu memiliki aspek layanan yang meliputi pengadaan dan pemasangan atau perbaikan serta pemeliharaan. Profesionalisme merupakan falsafah yang menjadi pegangan Ahlibrangkas.com dalam memberikan layanan kepada mitra kerja. Dengan dukungan tenaga ahli/tim kerja yang berpengalaman, perangkat yang memadai, serta Manajeman yang baik membuat perusahaan ini yakni bahwa Ahlibrangkas.com ini didirikan untuk membantu para konsumen yang mengalami kesulitan dari setiap brankas yang bermasalah.

\section{Struktur Organisasi dan Fungsi}

Struktur organisasi menspesifikasikan pembagian aktivitas kerja dan menunjukkan bagaimana fungsi atau aktivitas yang beraneka macam dihubungkan sampai batas tertentu, juga menunjukkan tingkat spesifikasi aktivitas kerja. Struktur organisasi dari Ahlibrangkas.com adalah sebagai berikut :

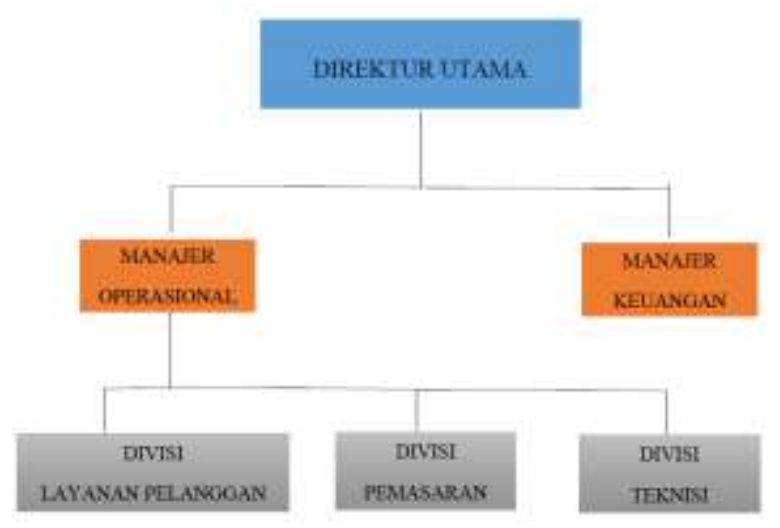

Gambar 1 Struktur Organisasi AhliBrangkas.com

\section{Prosedur Sistem Berjalan}

Dalam sebuah perusahaan yang bergerak di bidang jasa tentunya terdapat sebuah sistem informasi melakukan jasa perbaikan (service). Prosedur system berjalan yang diterapkan pada tiap perusahaan juga berbeda-beda. Prosedur jasa perbaikan (service) yang diterapkan di Ahlibrangkas.com ini masih menggunakan sistem manual yaitu melihat informasi melalui website dan menghubungi layanan pelanggan.

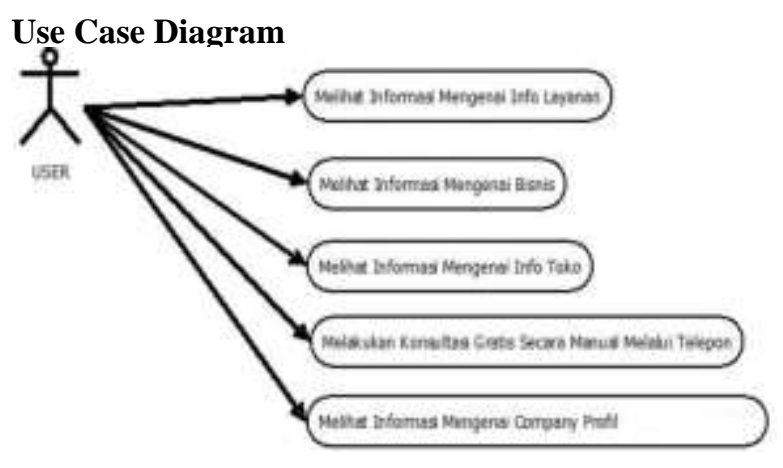

Gambar 2 Use Case Diagram

\section{Permasalahan Pokok}

Masalah yang sering terjadi dan dapat dilakukan perubahan system penjualan yang sebelumnya dilakukan dengan cara manual menjadi suatu sistem informasi jasa perbaikan brankas berbasis website, yang mampu membantu manajemen transaksi perusahaan dan memudahkan konsumen dalam melakukan perbaikan brankas.

\section{Pemecahan Masalah}

Membuat suatu sistem informasi jasa perbaikan brankas berbasis website agar memudahkan konsumen untuk bertransaksi dimanapun \& kapanpun.

\section{Hasil dan Pembahasan}

\section{Rancangan Diagram Use Case}

Sebuah use case mempresentasikan sebuah interaksi antara User dengan system serta Admin dengan system, berikut ini merupakan use case diagram dari Sistem Informasi Jasa Perbaikan Brankas yang diusulkan :

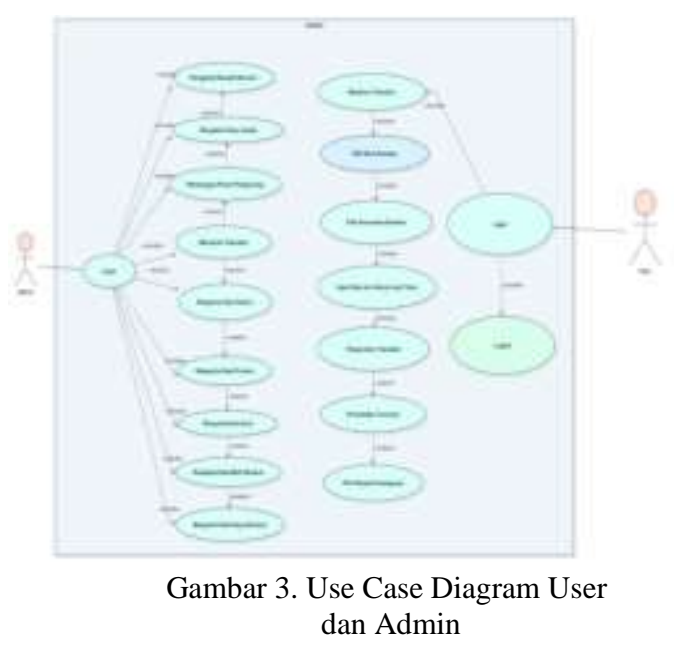




\section{Definisi Actor}

\begin{tabular}{|c|c|l|}
\multicolumn{2}{c|}{ Tabel 2. Tabel Definisi Actor } \\
\hline No. & Actor & \multicolumn{1}{c|}{ Deskripsi } \\
\hline 1. & Admin & $\begin{array}{l}\text { Orang yang bertugas dan } \\
\text { memiliki hak akses untuk } \\
\text { melakukan operasi pengelolaan } \\
\text { data transaksi, teknisi, provinsi, } \\
\text { kota, merk brankas, masalah } \\
\text { brankas, harga brankas,tanya } \\
\text { jawab serta menanggapi pesan } \\
\text { pengunjung. }\end{array}$ \\
\hline 2. & User & $\begin{array}{l}\text { Pengguna yang diperbolehkan } \\
\text { memilih merk brankas beserta } \\
\text { dengan kerusakannya } \\
\text { disesuaikan dengan keperluan } \\
\text { pengguna untuk melakukan } \\
\text { perbaikan brankas. }\end{array}$ \\
\hline
\end{tabular}

\section{Definisi Use Case}

\begin{tabular}{|c|l|l|}
\multicolumn{2}{|c}{ Tabel 3. Tabel Definisi Use Case } \\
\hline No. & \multicolumn{1}{|c|}{ Use Case } & \multicolumn{1}{c|}{ Deskripsi } \\
\hline 1. & Login / Register & $\begin{array}{l}\text { Proses User memasukkan data } \\
\text { diri pada halaman website dan } \\
\text { sistem menyimpan ke basis } \\
\text { data. }\end{array}$ \\
\hline $\mathbf{2 .}$ & $\begin{array}{l}\text { Membuat } \\
\text { Transaksi }\end{array}$ & $\begin{array}{l}\text { Proses User melakukan } \\
\text { transaksi. }\end{array}$ \\
\hline $\mathbf{3 .}$ & Pilih Merk & $\begin{array}{l}\text { Proses User untuk memilih } \\
\text { merk brankas disesuaikan } \\
\text { dengan kendala yang User } \\
\text { miliki dengan brankasnya. }\end{array}$ \\
\hline $\mathbf{4 .}$ & $\begin{array}{l}\text { Pilih Kerusakan } \\
\text { Brankas }\end{array}$ & $\begin{array}{l}\text { Proses User untuk melakukan } \\
\text { memilih jenis kerusakan pada } \\
\text { brankas disesuaikan dengan } \\
\text { kendala yang User miliki } \\
\text { dengan brankasnya. }\end{array}$ \\
\hline $\mathbf{5 .}$ & $\begin{array}{l}\text { Input Data dan } \\
\text { Alamat Janji } \\
\text { Temu }\end{array}$ & $\begin{array}{l}\text { Merupakan proses pengisian } \\
\text { data domisili seperti alamat } \\
\text { yang akan digunakan untuk } \\
\text { janji bertemu dilengkapi } \\
\text { dengan tanggal bertemu untuk } \\
\text { melakukan perbaikan. }\end{array}$ \\
\hline
\end{tabular}

\begin{tabular}{|c|c|c|}
\hline & & dan pembatalan transaksi \\
\hline 8. & $\begin{array}{l}\text { Pilih Metode } \\
\text { Pembayaran }\end{array}$ & $\begin{array}{l}\text { Proses pemilihan metode } \\
\text { pembayaran jika teknisi sudah } \\
\text { melakukan proses perbaikan } \\
\text { brankas }\end{array}$ \\
\hline 9. & Login Admin & $\begin{array}{l}\text { Merupakan proses masuk ke } \\
\text { dalam website. }\end{array}$ \\
\hline 10. & $\begin{array}{l}\text { Mengelola } \\
\text { Transaksi }\end{array}$ & $\begin{array}{l}\text { Proses menampilkan seluruh } \\
\text { jenis transaksi yang sudah } \\
\text { diterima. }\end{array}$ \\
\hline 11. & $\begin{array}{l}\text { Mengelola Data } \\
\text { Teknisi }\end{array}$ & $\begin{array}{l}\text { Proses mengelola data diri } \\
\text { teknisi yang bertugas. }\end{array}$ \\
\hline 12. & $\begin{array}{l}\text { Mengelola Data } \\
\text { Provinsi }\end{array}$ & $\begin{array}{l}\text { Merupakan proses mengelola } \\
\text { data Provinsi di sesuaikan } \\
\text { dengan wilayah yang dapat di } \\
\text { kunjungi Ahlibrangkas.com. }\end{array}$ \\
\hline 13. & $\begin{array}{l}\text { Mengelola Data } \\
\text { Kota }\end{array}$ & $\begin{array}{l}\text { Merupakan proses mengelola } \\
\text { data Kota di sesuaikan dengan } \\
\text { wilayah yang dapat di } \\
\text { kunjungi Ahlibrangkas.com. }\end{array}$ \\
\hline 14. & $\begin{array}{l}\text { Mengelola Data } \\
\text { Merk Brankas }\end{array}$ & $\begin{array}{l}\text { Merupakan proses mengelola } \\
\text { seluruh jenis brankas yang } \\
\text { dapat diperbaiki. }\end{array}$ \\
\hline 15. & $\begin{array}{l}\text { Mengelola Data } \\
\text { Harga Brankas }\end{array}$ & $\begin{array}{l}\text { Merupakan proses mengelola } \\
\text { harga tariff perbaikan yang di } \\
\text { sesuaikan dengan jenis } \\
\text { brankas yang sudah diperbaiki. }\end{array}$ \\
\hline 16. & $\begin{array}{l}\text { Mengelola } \\
\text { Masalah } \\
\text { Brankas }\end{array}$ & $\begin{array}{l}\text { Merupakan proses mengelola } \\
\text { masalah atau kerusakan pada } \\
\text { setiap jenis brankas. }\end{array}$ \\
\hline 17. & $\begin{array}{l}\text { Mengelola } \\
\text { Tanya Jawab }\end{array}$ & $\begin{array}{l}\text { Proses mengelola Tanya jawab } \\
\text { yang mempermudah user } \\
\text { mendapatkan informasi. }\end{array}$ \\
\hline 18. & $\begin{array}{l}\text { Menanggapi } \\
\text { Pesan } \\
\text { Pengunjung }\end{array}$ & $\begin{array}{l}\text { Proses menanggapi keluhan } \\
\text { user/pengunjung website } \\
\text { secara via-chat }\end{array}$ \\
\hline 19. & Logout & Proses keluar dari akun saya \\
\hline
\end{tabular}




\section{Diagram Aktivitas User}

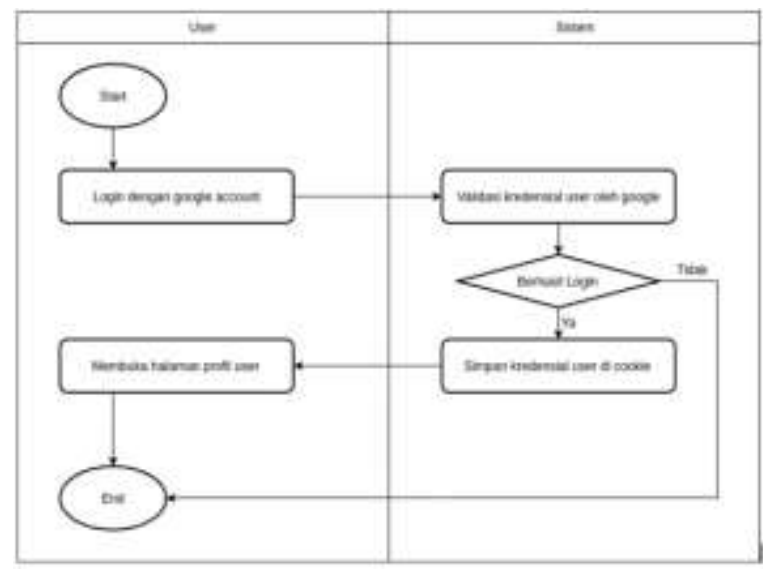

Gambar 4 . Aktivitas Admin

\section{Diagram Aktivitas Transaksi}

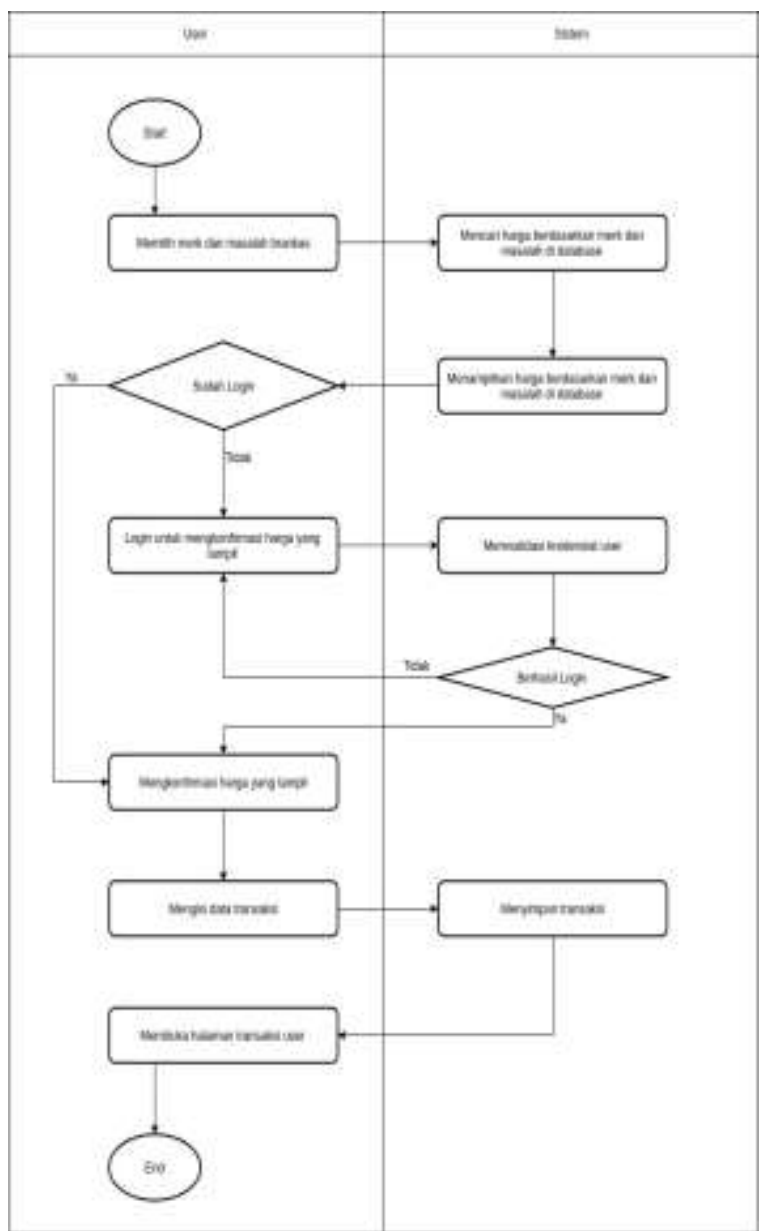

Gambar 5. Aktivitas Transaksi Users

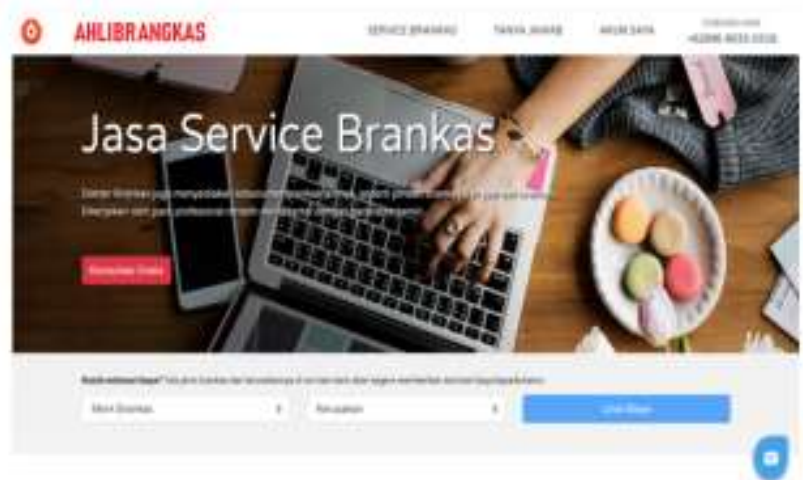

Gambar 6 Home Ahlibrangkas.com

Hasil dari pemesanan jasa perbaikan brankas adalah dalam bentuk laporan, dimana tertera nama dari pemesan beserta waktu janji temu serta alamat dan teknisi yang bertugas.
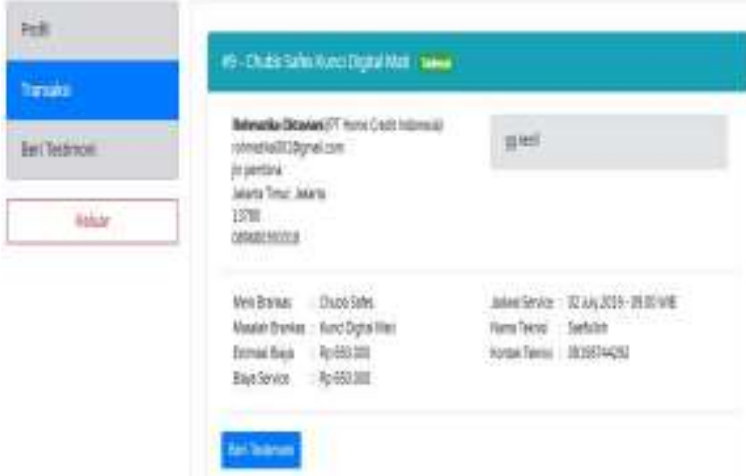

Gambar 7 Bukti pemesanan jasa perbaikan brankas

Setelah melakukan pemesanan, maka customer bisa melakukan pembayaran pada website
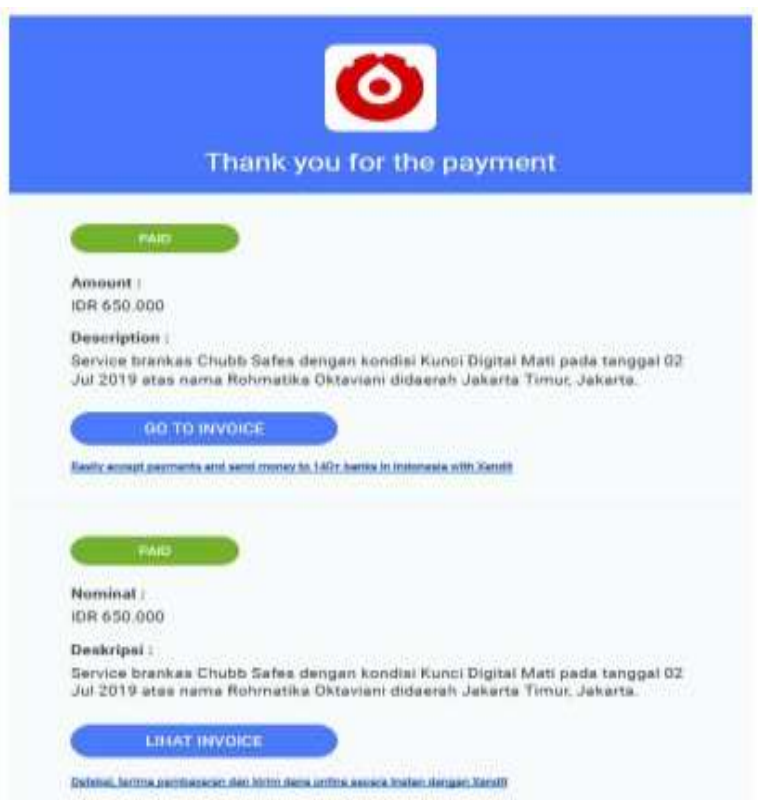

Gambar 8 Bukti melakukan pembayaran 
Hasil dari pemesanan serta pembayaran sudah diterima, maka admin dapat melakukan pengecekan langsung pada sistem.
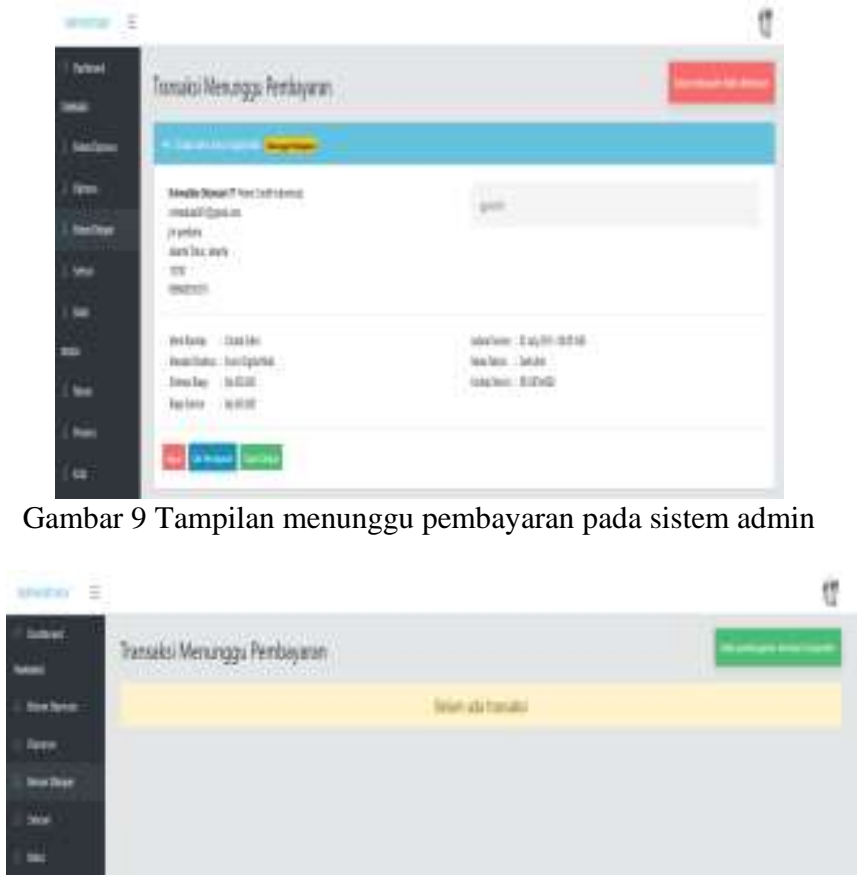

Gambar 10 Proses Transaksi sudah di bayarkan oleh customer pada sistem admin

\section{Simpulan}

Kesimpulan yang dapat saya ambil dari perancangan sistem informasi jasa perbaikan brankas pada Ahlibrankas.com adalah sebagai berikut:

1. Sistem informasi jasa perbaikan brankas berbasis website yang diusulkan mampu memudahkan pengguna untuk melakukan pemesanan secara online .

2. Sistem informasi jasa perbaikan brankas berbasis website ini menghasilkan laporan kegiatan perbaikan brankas dengan cepat dan akurat, memudahkan admin untuk melakukan pengolahan data laporan kegiatan perbaikan sehingga dapat mengurangi masalah human error.

3. Sistem informasi jasa perbaikan brankas berbasis website ini juga memudahkan karyawan yang sedang bertugas dilapangan menjadi lebih efektif.

Dari Kesimpulan diatas maka, Penulis membuat Saran :

1. Diharapkan untuk perusahaan dimasa yang akan datang dapat mengembangkan sistem dengan jual beli suku cadang brankas.

2. Diharapkan dilakukan Maintenance terhadap sistem informasi ini dan dilakukan backup secara berkala.

3. Diharapkan untuk perusahaan dikembangkan kembali untuk cangkupan jasa perbaikan brankas agar memperluas segmen pasar pelanggan.

\section{Kepustakaan}

[1] Agus, P., \& Safitri, Y. (2015). Pemanfaatan Sistem Informasi Perpustakaan Digital Berbasis Website Untuk. Indonesian Journal on Software Engineering, 1(1), 1-10. Retrieved from https://ejournal.bsi.ac.id/ejurnal/index.php/ijse/article/viewFile/59 $\underline{2 / 483}$

[2] Edy Winarno, S. T., M. Eng, and Ali Zaki. Pemrograman Web Berbasis
php, dan $\quad$ Javascript. Elex Media Komputindo, 2014.

[3] Hutahean, J. (2014). Konsep Sistem Informasi. In Climate Change 2013 - The Physical Science Basis (Vol. 53). https://doi.org/10.1017/CBO9781107415324.004

[4] Imaniawan, F. F. D., \& Nur, H. M. (2019). Perancangan dan Pembuatan Website Penjualan Biji Kopi Pada Society Coffee House Purwokerto Fabriyan. Evolusi Volume, 7(1), 61-67.

[5] Lubis, Adyanata. Basis Data Dasar. Deepublish, 2016.

[6] Mulyani, Sri. Metode Analisis dan Perancangan Sistem. Abdi Sistematika, 2017.

[7] Saryoko, A. (2015). Perancangan Sistem Informasi Penjualan Furniture Berbasis Web Pada Pk. Bumi Jaya Bekasi. Perspektif:JURNAL EKONOMI, SAINS DAN MANAJEMEN, XIII(1), 9-19. Retrieved from https://ejournal.bsi.ac.id/ejurnal/index.php/perspektif/article/view/ $\underline{1100 / 882}$

[8] Setyawan, A., Muttaqin, Z., \& Angpa, M. S. S. (2019). Aplikasi Pengadaan Barang Berbasis Web Pada Pt. Powerblock Indonesia. E-Jurnal.Lppmunsera.Org, 6(1), 73-77. Retrieved from http://ejurnal.lppmunsera.org/index.php/PROSISKO/article/view/1129

[9] Shalahuddin, Muhammad, and Arianti S. Rosa. "Rekayasa perangkat lunak terstruktur dan berorientasi objek." Bandung: Informatika (2016).

[10] Yatini, I. (2014). Aplikasi pengolahan citra berbasis web menggunakan javascript dan jquery. Jurnal Teknik, 3(3), 1-8. 